Institute of $\mathbf{F}_{\text {ood and }} \mathbf{A}_{\text {gricultural }} \mathbf{S}_{\text {ciences }}$

\title{
Landscaping Backyards for Wildlife: Top Ten Tips for Success 1
}

Mark E. Hostetler, Gregg Klowden, Sarah Webb Miller, Kara N. Youngentob²

In Florida, urban areas are a dominant feature in the landscape, and many of these urban areas are situated near natural wildlife preserves. What people do in their own yards and neighborhoods affect local and nearby wildlife populations. Steps can be taken to create and save wildlife habitat in urban areas, minimizing our adverse impact on local wildlife. Plus, creating wildlife habitat provides wildlife viewing opportunities for people in cities.

Wildlife are affected by how homeowners manage their yards and neighborhoods at both local and regional scales (Figure 1). For example, maintaining a habitat for wildlife in a yard increases biodiversity in the neighborhood. (Biodiversity is simply the number of different species occurring in a given area.) On a larger scale, how one manages yards and neighborhoods can have a positive effect on surrounding habitat. For example, a neighborhood may separate natural areas. These natural areas can be connected if residents provide a corridor of natural vegetation through the neighborhood. Residents can plant natural vegetation in their individual yards so it is near or connected to vegetation in the next yard, and so on. This creates a corridor that animals can use to travel from one natural area to another, thus benefiting wildlife at a larger scale.

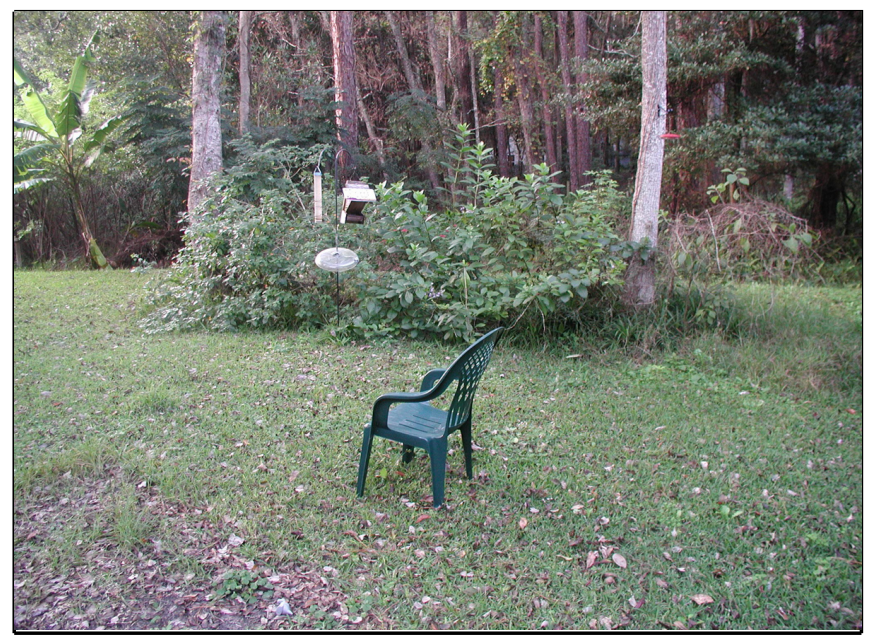

Figure 1. Yards can be designed and managed for both wildife and humans. Photo by Mark E. Hostetler.

However, neighborhoods can have a negative impact on both local and nearby wildlife habitat. People may plant invasive, exotic plants that invade nearby natural areas (for example, Chinese Tallow). The growth of these plants in natural areas destroys wildlife habitat. Also, pets may run loose in neighborhoods and nearby areas. Pets can disrupt

1. This document is Circular 1429, one of a series of the Department of Widlife Ecology and Conservation, Florida Cooperative Extension Service, Institute of Food and Agricultural Sciences, University of Florida. First published in January 2003. Please visit the EDIS Web site at http://edis.ifas.ufl.edu for more publications.

2. Mark E. Hostetler, Assistant Professor and Extension Wildlife Specialist; Gregg Klowden, Doctoral Student; Sarah Webb Miller, Wildlife Extension Program Assistant; Kara N. Youngentob, Graduate Student; Dept. of Wildlife Ecology and Conservation, Institute of Food and Agricultural Sciences, Florida Cooperative Extension Service, University of Florida, Gainesville, FL 32611.

The Institute of Food and Agricultural Sciences is an equal opportunity/affirmative action employer authorized to provide research, educational information and other services only to individuals and institutions that function without regard to race, color, sex, age, handicap, or national origin. For information on obtaining other extension publications, contact your county Cooperative Extension Service office. Florida Cooperative Extension Service/Institute of Food and Agricultural Sciences/University of Florida/Christine Taylor Waddill, Dean. 
wildlife populations through hunting and harassment of animals. What people do within their own yards does affect nearby wildlife populations.

Collectively and as individuals, homeowners can do many different things to provide wildlife habitat. Essentially, wildlife habitat consists of food, cover, water, and space. However, providing habitat is not enough. One must manage the yard or neighborhood so that impacts are minimal. The suggestions below will guide homeowners to manage and design their yards and neighborhoods for wildlife.

\section{Ten Tips for Landscaping for Wildlife}

All these tips are of value to wildlife, so they are presented in random order.

1. Limit the Amount of Lawn

2. Increase Vertical Layering

3. Provide Snags and Brush Piles

4. Provide Water

5. Plant Native Vegetation

6. Provide Bird/Bat Houses and Bird Feeders

7. Remove Invasive Exotic Plants

8. Manage Pets

9. Reduce Pesticide Use

10. Expand the Scale of Habitat

\section{Tip 1: Limit the Amount of Lawn}

Lawn is like concrete to most species of animals. It offers very little food or cover. In general, we recommend reducing the amount of mowed lawn around your house, especially in areas of low traffic such as corners of the yard (Figure 2). By simply not mowing, you will be creating shelter and food for many animal species. Over time, unmowed areas contain more plant species than mowed areas. This plant diversity attracts more wildlife species. For example, birds are attracted to areas that are structurally diverse. These areas provide shelter in which to hide from predators or build nests. Further, the diversity of plants provides more feeding opportunities. More fruits and seeds can occur in these unmowed areas. Most importantly, diverse areas attract more insects and most birds eat insects.

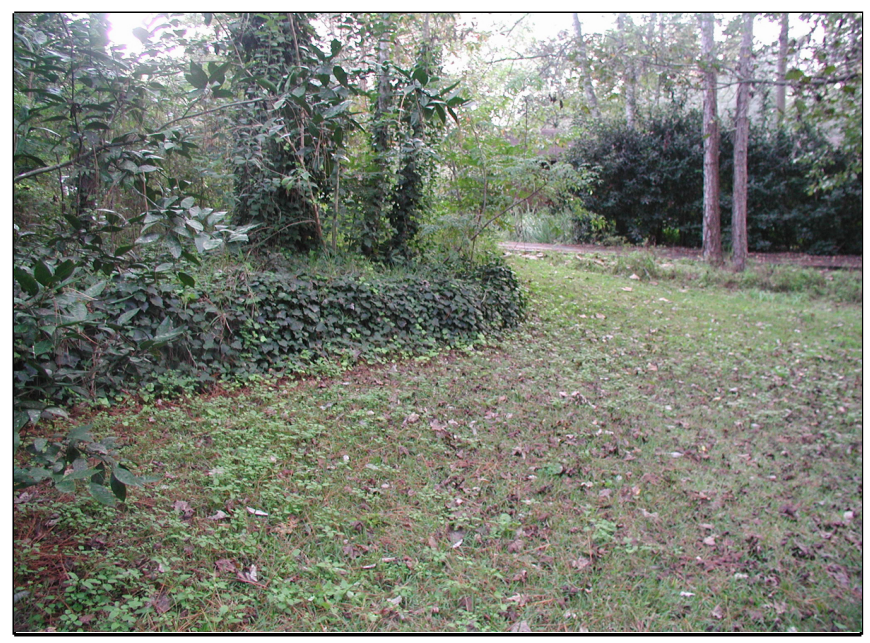

Figure 2. You can reduce mowed lawn by leaving low-traffic areas unmowed and by planting ground cover plants to replace grass. Photo by Mark E. Hostetler

Why does mowing favor grass? Mowing favors grass because it is adapted to being cut down. When you leave an area unmowed, other plants will gradually replace the grass. These plants may sprout from seeds already in the soil. Also, seeds could come from the surrounding area. Wind and water can bring a wide variety of seeds to a given place. As an area becomes more diverse, animals will visit the area and bring in more seeds. Seeds are stuck to their body or are found in their droppings. To help speed up the replacement of lawn, you can remove the grass and plant seeds of NATIVE wildflowers that are adapted to the conditions in that part of your yard (sunny, shady, wet, dry, etc.).

\section{Replace Some Lawn Grass with Ground} Cover Plants: Another option is to replace lawn with ground cover plants, which are more valuable to wildlife than lawn grass (Figure 3). Compared to ground cover plants, lawn grasses require a lot of maintenance -- mowing, fertilizing and watering -- all of which have high energy costs in electricity, water, and other natural resources. In general, yards have many areas where native ground covers would be attractive (under trees and bushes, or along a privacy fence). Ground covers also provide food and cover for small animals. For information on the benefits of 
ground covers, see this Web page at http://hort.ifas.ufl.edu/gt/groundcoverenergy/ groundcoverenergy.htm.

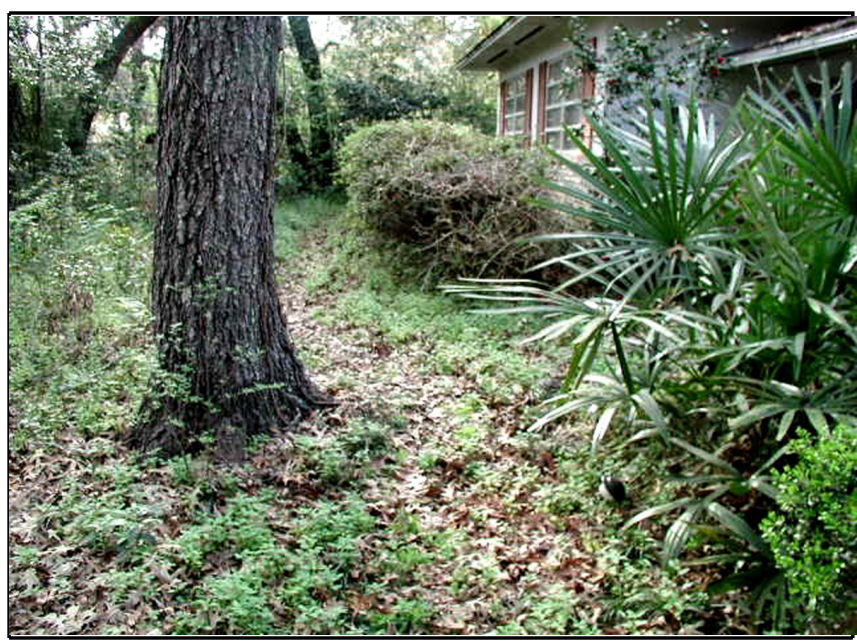

Figure 3. Ground covers provide habitat for a variety of wildife species, and they are easier to maintain than lawns. Photo by Mark E. Hostetler.

Add Islands of Vegetation: Islands of landscaped vegetation are also very helpful to wildlife. These can be planted with native ground cover, wildflowers, or other vegetation. If possible, locate the islands so they are near each other. Islands can also be located near unmowed areas of the yard (Figure 4). Overall, the nearer they are to each other, the more likely an animal will cross from one island to the next. A group of islands reduces the amount of open space animals have to cross. Animals that cross open areas are at greater risk of being prey for other species. Animals are more likely to use an island if it is located near another. Small, ground-dwelling wildlife species benefit greatly from islands of vegetation. Grouping islands of vegetation even benefits birds. Birds like to be near shelter while foraging for food.

Plant a Butterfly Garden: For butterfly habitat, add plants for both the adult butterflies and their larvae (caterpillars). They often feed on different species of plants. For information on which plants are utilized by butterfly larvae and by adults, see the free publication "Butterfly Gardening in Florida" on the Web at http://edis.ifas.ufl.edu/pdffiles/UW/UW05700.pdf, and the book titled Your Florida Guide to Butterfly Gardening by Jaret Daniels. If you do not have a computer, your local County Extension Agent can

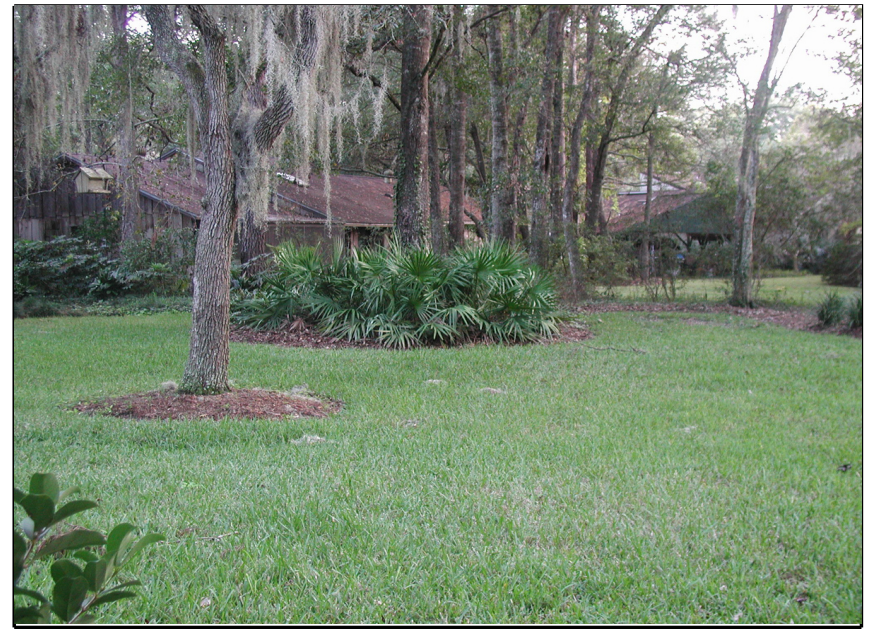

Figure 4. Replacing some lawn grass with islands of vegetation is beneficial to birds and small animals, and to you -- if you're the one who mows the lawn! Photo by Mark E. Hostetler

print a copy of the free publication for you. The book is available from the University of Floridas IFAS Book Store. To order Your Florida Guide to Butterfly Gardening, call 1-800-226-1764 or visit their Web site at http://ifas.books.ufl.edu.

Both of the above resources contain lists of plants that attract butterflies and tell which plants are native to Florida. When planting your butterfly garden, keep in mind that the food plants for larva (caterpillars) will be munched on and may look a little tattered at times.

Another way to help butterflies is to create a small, bare area of moist sand in your yard. This moist area is attractive to male butterflies in particular. They sip water from damp sand to obtain needed salts/minerals -- this behavior is called "puddling."

\section{Tip 2: Increase Vertical Layering}

Looking across your yard, do you see large trees, low grass, and nothing in between? Increasing plant structure between the ground and the tree canopy is called "vertical layering." Planting bushes or ground covers below some of your trees would benefit wildlife. Planting a variety of vegetation in different sizes and heights provides more cover and feeding opportunities for wildlife species. Clumps (or islands) of vegetation with plants of different heights are best (Figure 5). One example of vertical layering 
is a tree with medium-sized shrubs surrounding it and some ground covers planted around the shrubs. Use native plants whenever possible (more information below about native plants).

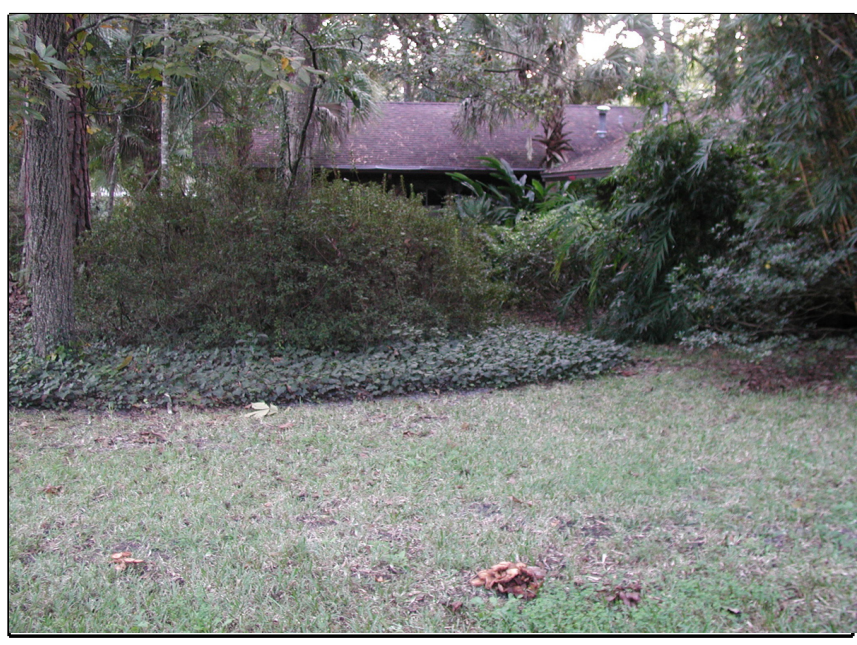

Figure 5. Notice the different heights of vegetation in this yard -- ground covers, shrubs, and trees. This "vertical layering" of vegetation is very beneficial to wildlife.

\section{Tip 3: Provide Snags and Brush Piles}

As trees become diseased or die, consider leaving them standing as "snags". Many wildlife species use snags for feeding and nesting. While nest boxes supply homes for many species, some woodpeckers will only use cavities they excavated themselves. Thus, the need for snags. Many of the insects that occur in snags are food for woodpeckers and other bird species.

If safety is a concern in leaving snags (dead trees) standing, ask a tree surgeon to cut the snag to about 15 feet tall. This will still be valuable to wildlife!

For those without a dead or dying tree, adding a small snag is an option. For example, you could obtain permission from a developer to remove small downed trees, or sections of downed trees, from a property. These snags could be placed in your yard (either propped upright, or laid down horizontally to provide a rotting $\log$ ).

A brush pile or two, especially if near other vegetation, will provide excellent cover and feeding opportunities for wildlife (small mammals, birds, and butterflies). This will also serve as cover in open areas.

\section{Tip 4: Provide Water}

Water is an essential part of productive wildlife habitats. Wildlife will benefit from any water source you provide, such as a birdbath and/or a small pond. Ponds are not only beautiful, but also attract a variety of species and enhance amphibian breeding. Please consult our free publications "Water for Wildlife" and "An Introduction to Aquascaping." These publications can be accessed through this Web site: http://www.wec.ufl.edu/extension/landscaping.htm.

\section{Tip 5: Plant Native Vegetation}

Plant NATIVE plant species in your yard whenever possible. Landscaping with plants that are native to Florida not only provides better food and cover for native wildlife than do non-native plants, but on average, requires less care and resources to maintain. As with all plants, newly planted native plants must be watered until they are established. But after they are established, Florida's native plants require less water because most are adapted to local water conditions. Native plants are better adapted to natural soil conditions and generally do not require fertilizing. They are more resistant to natural pests and diseases, so do not require pesticides.

Even with native plants, be sure to plant them in the specific conditions for their optimal growth (full sun, part sun/part shade, full shade, wet soil, dry soil, acidic soil, sandy soil, etc.). It's best to first take a look at the conditions in your yard: sunny and shady areas, wet areas, compare morning versus afternoon, etc. Then go buy the appropriate plants for the conditions in your yard.

Native plant species have evolved and adapted to local conditions over thousands of years. They are usually much more tolerant to climatic conditions at a given location. Once established, most species require little or no additional irrigation beyond normal rainfall. They typically grow more slowly, generating much less yard waste.

Each native plant species is a member of a community that includes other plants, animals, and 
micro-organisms. The natural balance keeps each species in check. Plants thrive in conditions to which they are adapted. However, other organisms (e.g., insects) prevent plants from spreading uncontrolled. Thus, native species rarely become invasive, unlike some exotic (non-native) plants imported from other areas that have no natural organisms here to keep their spread in check.

For more information on native plants, visit the Florida Native Plant Society Web site at http://www.fnps.org/. Information on where you can purchase native Florida plants can be found on the Association of Florida Native Nurseries Web site at http://www.afnn.org/.

If you want to know the specific benefits that each type of plant provides for wildlife, consult the booklet entitled Planting a Refuge for Wildlife. This booklet includes a list of trees, shrubs, and vines, and gives their specific value to wildlife (see last section of booklet). One copy of this booklet is available for free and can be obtained by sending a request for one copy to: Planting a Refuge, P.O. Box 1289, Woodville, FL 32362-1289. Additonal copies are 50 cents each. Make your check payable to the Florida Wildlife Federation, and write "Habitat Fund" in the Memo area on the check.

\section{Tip 6: Provide Bird/Bat Houses and Bird Feeders}

Bird Feeders: Adding birdfeeders of different designs or with different seeds may increase the diversity of birds you see on your property. If you add a hummingbird feeder, be sure to change water often, at least weekly during hot weather. Check it regularly to see if the solution becomes cloudy. If so, change it soon or it will make hummingbirds ill. Wash hummingbird feeders with just hot water and a little soap; do NOT use chlorine bleach when cleaning hummingbird feeders.

Wash all other birdfeeders and birdbaths regularly with soap and water or a solution of 1 part chlorine bleach to 10 parts water. We recommend cleaning with chlorine at least bi-monthly, or when the feeders and birdbaths are exceptionally dirty. Rinse well with warm water after cleaning. Wash wood or cement birdfeeders and baths with soap and warm water only (no chlorine). Remember to clean old or wet seeds out of the feeders or they will rot and make birds sick. Several lethal diseases can be transmitted between birds at feeders and birdbaths.

Locating the feeders near cover (bushes, trees) is helpful for songbirds if they have to escape a predator. However, keep feeders at least 15 feet away from vegetation so that squirrels cannot jump onto the feeder. Fifteen feet is still close enough to provide birds with some avenue of escape from predators. For more information, please see the Web site at http://birds.cornell.edu.

Bird and Bat Houses: Adding birdhouses (nest boxes) and bat houses in your yard will provide nesting and roosting shelter for wildlife. These resources will be used primarily by birds and bats, but other species will use these shelters if not occupied. For example: Flying squirrels and gray squirrels will roost in empty birdhouses (if entry hole is large enough).

What types of birds nest in birdhouses? How do you make your birdhouse attractive to birds, especially if you want to attract a particular species?

Cavity-Nesting Birds: The types of birds that nest in birdhouses (nest boxes) are called "cavity-nesting" species. They typically excavate holes in dead trees or use existing cavities (natural or bird-made). Cavity-nesting birds include woodpeckers, owls, chickadees, great-crested flycatchers, bluebirds, nuthatches, kestrels, wood ducks, etc. (Figure 6). Even small mammals such as flying squirrels will roost in nest boxes! In urban areas, cavity-nesting birds may not be able to find enough natural cavities for nesting. That makes birdhouses a valuable habitat resource for these birds.

Some cavity-nesting birds are primary cavity-nesters and some are secondary cavity-nesters. Primary cavity-nesters (woodpeckers) excavate their own cavities, usually in dead or dying trees (there are a few exceptions). Secondary cavity-nesters (bluebirds, chickadees, owls, great-crested flycatchers, etc.) don't make their own cavity. They use a cavity that has been excavated by a primary cavity-nesting bird, or they use a natural cavity if they 
can find one. Secondary cavity-nesting birds are the species most likely to use your birdhouse(s).

Provide snags (dead trees) for primary cavity-nesters, and provide birdhouses for secondary cavity-nesting species (Figure 6).

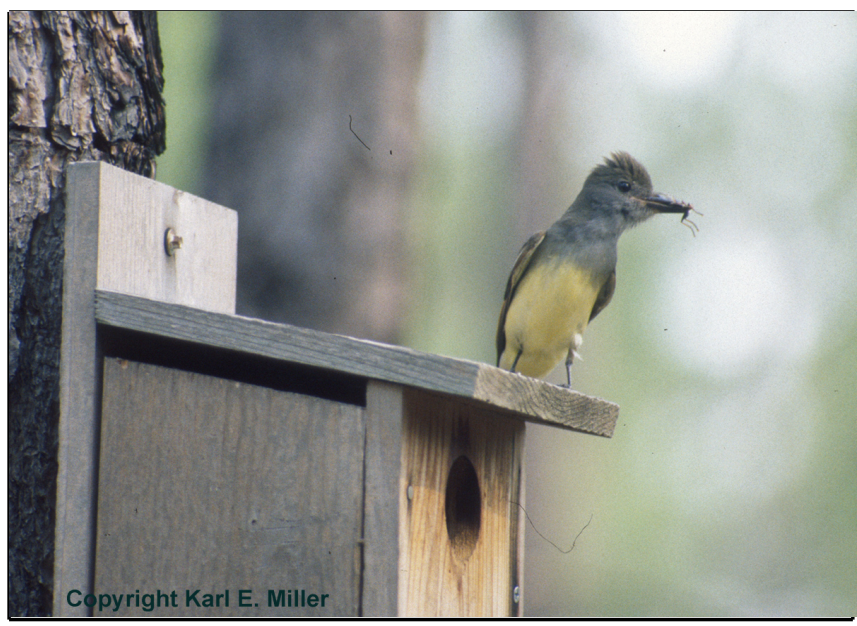

Figure 6. Many birds will nest in birdhouses (nest boxes). Here, a Great-crested Flycatcher perches atop a nest box. Photo copyrighted by Karl E. Miller.

Making a Birdhouse Attractive to Birds: So, which birds will use your birdhouse? That is determined by several factors, including:

- the size of birdhouse (overall size, as well as depth)

- the size of the entry hole

- the height at which the birdhouse is mounted

- the amount of surrounding vegetation (lack of, presence of, size of, etc.), and

- the habitat adjacent to your yard, in your neighborhood.

When you know a bird species' requirements, then you can look for suitable locations to mount the birdhouse, or nest box, in your yard. Your birdhouse could be mounted on a freestanding post or on a tree. For recommendations on building birdhouses and nest boxes, see our free publication "Helping Cavity-nesters in Florida" on the Web at http://edis.ifas.ufl.edu/UW058. This publication will help you decide on the best birdhouse (nest box) design for the species you see in your yard, or want to attract, and the proper placement of the birdhouse in your yard. Other articles can be found on our Landscaping for Wildlife Web page at http://www.wec.ufl.edu/extension. In addition, the Cornell Lab of Ornithology provides dimensions for nest boxes for many different bird species on their Web page called The Birdhouse Network, at http://www.birds.cornell.edu/birdhouse/bhbasics/ bhbasics_index.html.

\section{Tip 7: Remove Invasive Exotic Plants}

Some species of exotic (non-native) plants are highly invasive and should not be planted. Invasive exotic plants aggressively take over natural habitat -altering natural ecology of an area and sometimes replacing all native vegetation.

Approximately 1.7 million acres of Florida's remaining natural areas have been invaded by exotic plant species. In fact, invasive exotic pest plants destroy more natural habitat every year than development. These exotic plant invasions degrade and diminish what remains of Florida's natural areas.

When it comes to exotic non-native plants, what we do in our individual yards can affect areas far beyond our yards. The seeds of non-native invasive plants are designed to be easily carried far away by wind, water, birds, and other animals. Once established, these non-native plants then overpower and replace native plants, thus destroying wildlife habitat and altering the natural ecology of a site. This results in areas with fewer plant species and fewer feeding and cover opportunities for wildlife.

In some cases, such as with Australian Pine, Brazilian Pepper, Kudzu, and Melaleuca, a complete loss of ALL native plants may occur. This results in areas with only a single invasive plant species. The effects of this loss of native vegetation are detrimental to wildlife. Wildlife may have relied on a plant that no longer occurs in an area. Domination by a single non-native plant species is especially destructive because wildlife generally need a variety of plants for cover and food. These changes can be especially detrimental to endangered species. Many endangered species rely on specific features found only in their natural ecosystems. Further, non-native plants can alter natural wildfire patterns. In some 
situations, they can cause increased wildfire frequency and intensity. Endangered plants, animals, and native ecosystems are being pushed closer to extinction by invasive exotic plants. For more information, go to http://plants.ifas.ufl.edu.

Before buying plants for your landscape, consult the list of invasive exotic plants on the Florida Exotic Pest Plant Council Web site so you will know which plants to avoid (http://www.fleppc.org/Plant_list/list.htm).

Other helpful Web sites include:

- University of Florida, IFAS, Center for Aquatic and Invasive Plants at http://plants.ifas.ufl.edu

- University of Florida Web site with photographs of aquatic and wetland plants and invasive plants at http://aquat1.ifas.ufl.edu/photocom.html

- University of Florida, Wildlife Extension at http://www.wec.ufl.edu/extension

\section{Tip 8: Manage Pets}

Pets can have a huge impact on wildlife. Both dogs and cats can drastically impact wildlife populations. Cats are extremely good at hunting. Their small size, agility, and speed are a lethal combination for the small animals on which they prey. Loose dogs will also harass and even kill a wide variety of wildlife species. Scientists estimate that cats are responsible for killing hundreds of millions of birds and possibly more than a billion small mammals in the U.S. each year. Just because an animal is well-fed does not mean that it won't hunt. Cats and dogs hunt for fun, not necessarily for food. A well-fed pet or stray is even more adept at hunting since it has a lot of energy. Pet predation is especially problematic if you are attracting birds and other wildlife to your yard. Please take steps to insure that your yard is not the last yard that these wild animals will ever visit.

Contact your county's Animal Control shelter or the local Humane Society immediately if you see a stray animal in your neighborhood. Please never attempt to approach an unknown stray animal or wildlife for any reason. Also, do not offer food to stray animals. Feeding strays will increase local populations.

Keeping cats exclusively indoors is strongly supported by the animal welfare, veterinary, conservation, and scientific communities. Making sure that your cats stay indoors will keep them safe from other strays, traffic, and many diseases that can be transmitted to your pet through contact with wild animals. If you still feel that it is important for your cats to spend time outside, consider a screened-in patio or even leash training, which many cats (especially Siamese) can learn to accept. It is important though that you never leave your cat on a leash when you are not around because it can easily get tangled and choke.

\section{Information on the American Bird}

Conservancy's Cats Indoors campaign is available on the Web at http://www.abcbirds.org/cats/catsindoors.htm. Also, the California Department of Fish and Game has a wealth of information about this issue available at http://www.dfg.ca.gov/hcpb/cats_wildlife.html. Additional information can be found on the Humane Society of the United States Web site at http://www.hsus.org/programs/companion/ pet_cruelty/freeroaming_statement.html and the National Audubon Society Web site at http://www.audubon.org/bird/cat/.

Further, a variety of released exotic pets can impact wildlife. Releasing exotic pets can cause dire consequences for natural habitats and wildlife. "Exotic" pets include parrots, giant toads, and almost any animal bought at a pet store because most of these animals are originally from other parts of the world. These exotic pets could establish themselves in the wild. They may actually compete with native wildlife for food and shelter. Further, some carry diseases that may infect local wildlife. For example, pet turtles are thought to have transmitted a respiratory disease to gopher tortoises.

\section{Tip 9: Reduce Pesticide Use}

Anything you can do to reduce pesticides in your yard will benefit wildlife. Most pesticides do not target one species of insect but will kill any type of insect that comes in contact with it. Thus, when you 
spray your yard with pesticides to kill one pest species, you are also killing lots of beneficial species. Almost all wildlife species eat insects in some way. Wildlife, and even humans, are truly connected to insects. Most birds, reptiles, amphibians and mammals eat insects. Even if they do not eat insects directly, their prey eat insects. For example, some hawks eat smaller birds. Some of these smaller birds eat insects. Essentially, if you have good insect diversity, you have good wildlife diversity.

Further, many insects provide a valuable service in the environment. They pollinate plants. Insect pollinators include flies, bees, wasps, beetles, moths, butterflies, and other insects. As they feed on flower nectar, they carry pollen from flower to flower which promotes plant reproduction. Without pollinating insects, some plant species may not reproduce in a local area. This change in plant diversity ultimately will affect wildlife diversity. These plants might have provided food and shelter for various animals.

Without the plants, many wildlife species may not be able to survive in the immediate area.

Instead of broadcasting pesticides over a large area, spot treat or use baits that target one pest species. If you spray indiscriminately, you also kill the natural predators of pest insects. The pests will actually come back much quicker than their predators. Encourage insects that eat pest species. For example, encourage ladybugs to live in your garden. They eat aphids. Allow spiders and paper wasps to exist around your house. They eat lots of kinds of insects. Did you know that some birds eat spiders? Also, hummingbirds use spider webs in building their nests.

Some plants, such as marigolds, deter insects. Visit the following Web site to learn about environmentally friendly ways to discourage insects from invading your yard: The Natural Garden -Organic Pesticides, http://www.geocities.com/heartland/meadows/1322/ organic.htm

\section{Tip 10: Expand the Scale of Habitat}

The required habitat for many species is much larger than what you could provide within your yard. Consider talking with your neighbors about creating larger wildlife habitat patches. The combination of several different yards with wildlife habitat will draw more species into the neighborhood and, thus, more to your yard. Many wildlife species prefer large patches of their preferred habitat (such as open meadow, shrubs, or mixed forest). Some species primarily respond to one type of habitat. Other species like a mixture of different habitats. For example, Red-eyed Vireos like primarily forested habitats. Northern Mockingbirds like a mixture of shrubs, trees, and open areas.

In particular, larger species respond to landscape structure (such as tree canopy) at much broader scales than do smaller species. For example, a Red-tailed Hawk will respond to landscape structure across a whole neighborhood. A Carolina Wren will probably respond to landscape structure within one or two backyards.

Discuss with your neighbors about designing wild areas at the property lines or on adjacent corners of your properties. Utilize land where people traffic is low. This will create larger habitat patches for wildlife. Even creating wildlife habitat with neighbors that are not adjacent to your property creates a number of different habitat patches. This design would make your neighborhood attractive to more species. For more information, visit http://www.nwf.org/nationalwildlife/1998/ perceive.html.

\section{Additional Suggestion}

\section{Interested in Monitoring Birds?}

Do you like attracting birds to your yard? The Department of Wildlife Ecology and Conservation's Wildlife Extension office, in conjunction with IFAS Information Technologies, developed the Florida Bird Monitoring Program. The objective of the Florida Bird Monitoring Program is to provide a Web site where participants can enter and view bird survey data collected by themselves and others around the state. Homeowners and participants from natural resource, Cooperative Extension, and education programs are encouraged to participate. 
Which types of birds are visiting a yard or neighborhood? Through this Web site, you can track which birds occur in your yard and community over time. If you are a property owner who is landscaping to attract birds, you can monitor which landscaping strategies and management techniques worked best. By participating in this bird monitoring program, you can see how these techniques affected birds in your yard. You can also monitor the quantity and types of birds that visit any area throughout the state from month to month or year to year. For more information on how to join, visit our Web site at http://bird.ifas.ufl.edu.

\section{More Resources}

Barnett, M.R. and D.W. Crewz. 1997. Common Coastal Plants in Florida: A Guide to Planting and Maintenance. University Press of Florida:Gainesville.

Beriault, J.G. 1995. Planning and Planting a Native Yard. Florida Native Plant Society:Vero Beach, FL. Web site: http://www.fnps.org, Phone: (772) 462-0000, Email address: info@ fnps.org.

Bowman, S., Inc., Suncoast Native Plant Society. 1997. The Right Plants for Dry Places: Native Plant Landscaping in Central Florida. Great Outdoors Publishing Company:St. Petersburg, FL. Web site: http://www.floridabooks.com/contact.html

Daniels, J.C. 2000. Your Florida Guide to Butterfly Gardening: A Guide for the Deep South. University Press of Florida:Gainesville.

Gilman, E.F. and R.J. Black. 1999. Your Florida Guide to Shrubs: Selection, Establishment and Maintenance. University Press of Florida:Gainesville.

Huegel, C.N. Butterfly Gardening with Florida's Native Plants. Florida Native Plant Society:Vero Beach, FL. Web site: http://www.fnps.org, Phone: (772) 462-0000, Email address: info@fnps.org.

Huegel, C.N. 1995. Florida Plants for Wildlife: A Selection Guide to Native Trees and Shrubs. Florida Native Plant Society:Vero Beach, FL. Web site: http://www.fnps.org, Phone: (772) 462-0000, Email address: info@fnps.org.
Langeland, K.A. and K.C. Burks. 1998. Identification and Biology of Non-Native Plants in Florida's Natural Areas. University of Florida, Institute of Food and Agricultural Sciences. Publication \# SP257. Available from IFAS Bookstore online at:

http://ifasbooks.ufl.edu/merchant2/merchant.mv

Minno, M.C., M. Minno, D. Pierce, and T.C. Emmel. 1999. Florida Butterfly Gardening: A Complete Guide to Attracting, Identifying, and Enjoying Butterflies of the Lower South. University Press of Florida:Gainesville.

Osorio, R. 2001. A Gardener's Guide to Florida's Native Plants. University Press of Florida:Gainesville.

Schaefer, J. and G. Tanner. 1998. Landscaping for Florida's Wildlife. University Press of Florida:Gainesville.

Traas, P.F. 1999. Gardening for Florida's

Butterflies. Great Outdoors Publishing Company:St. Petersburg, FL. Web site:

http://www.floridabooks.com/contact.html

Watkins, J.V. and T.J. Sheehan. 1986. Florida Landscape Plants: Native and Exotic. University Press of Florida:Gainesville. 